\title{
Liderazgo y educación: hacia una gestión educativa de calidad
}

\section{Leadership and Education: towards a quality educational management}

\author{
Armando Chacón Mora ${ }^{1}$ \\ Ministerio de Educación Pública \\ San José, Costa Rica \\ armachacon@gmail.com
}

\begin{abstract}
Recibido 22 octubre 2011 * Aceptado 31 octubre 2011 * Corregido 14 diciembre 2011
\end{abstract}
\begin{abstract}
Resumen. Cada etapa de la historia evidencia acontecimientos significativos para la humanidad. La sociedad actual brinda una serie de retos a la educación costarricense, los cuales en lugar de convertirse en un obstáculo, se presentan como posibilidades para la evolución, crecimiento y el mejoramiento educativo. Estas mutaciones socioculturales son consecuencia de la génesis y desarrollo de un nuevo paradigma: el científico-tecnológico, el cual ha ido cambiando vertiginosamente el ser y el proceder de las personas. Todas estas transformaciones y cambios que se producen en el núcleo mismo de las culturas y los pueblos, son en gran parte fruto del fenómeno denominado como globalización. Por esto, es importante rediseñar el currículo educativo nacional para que se constituya en un sistema que implemente una nueva forma de educar y de potenciar el liderazgo, el cual debe de ser práctico y contextualizado a la realidad de la sociedad costarricense; buscando sobre todo mejorar la calidad de vida de todas las personas. Una educación por y para el liderazgo, constituye un factor determinante para el perfeccionamiento de la calidad educativa que incide en la sociedad, lo que busca ante todo el desarrollo integral de la persona y las personas que conviven socialmente.
\end{abstract}

Palabras clave. Liderazgo transformacional, educación, calidad educativa, líder, globalización.

Abstract. Each stage of history evidences significant events for humanity. The current society provides challenges to education in Costa Rica, which instead of becoming an obstacle, they are presented as opportunities for development, growth and educational strengthening. These sociocultural mutations are the result of genesis and development of a new paradigm: the science and technology, which has been changing rapidly the being and behavior of people. All these transformations and changes that occur in the heart of cultures and peoples are largely the result of a phenomenon known as globalization. Therefore, it is important to redesign the national educational curriculum that is constituted in a system that implements a new way to educate and

${ }^{1}$ Doctor en Educación de la Universidad Católica de Costa Rica. Magíster en Ciencias de la Educación con énfasis en Administración Educativa de la Universidad de Costa Rica. Actualmente labora como director del Liceo Experimental Bilingüe de la Trinidad de Moravia. 
Revista Gestión de la Educación, Vol.1, №2, pp.144-165, ISSN 2215-2288, julio-diciembre, 2011

empower leadership, which must be practical and contextualized to Costa Rican society, seeking to improve welfare and quality life for people. An education for leadership is a determining factor for improving educational quality that affects society, which seeks integral development of an individual and people living socially.

Key words. Transformational leadership, education, educational quality, leader, globalization.

\section{Educación y liderazgo}

Es una realidad que, en la actualidad, el comportamiento social, las formas de pensamiento y las costumbres de las generaciones presentes han evolucionado y con ellas sus valores, creencias, patrones de conducta y comportamientos. Estamos ante un fenómeno social complejo, algo parecido a lo que Kuhn denominó como un "paradigma".

Un paradigma surge en tanto que se demuestra que una teoría es superior a las existentes, esta entonces es aceptada y produce una "revolución científica". Dichas rupturas revolucionarias obligan a la sociedad misma a hacer cambios de los conceptos científicos, para dar una respuesta a los nuevos problemas, que surgen con una metodología adecuada. La educación costarricense se enfrenta al reto del paradigma científico-tecnológico, el cual también se ve influido por el sistema económico capitalista neoliberal. De acuerdo con Sánchez (2011):

Kuhn identifica el paradigma con un tipo de Weltanschauung, un modo de ver el mundo, un contexto histórico-social dentro del cual se articulan y determinan hechos, datos y teorías, y en el que adquieren significado los términos allí empleados. En estas circunstancias el término paradigma se aplica a todo aquello que está sujeto al consenso de una comunidad científica. Un paradigma es lo que los miembros de una comunidad científica comparten; y a la inversa, la posesión de un paradigma común es lo que constituye en comunidad científica a un grupo cualquiera de hombres. (p.1)

Hoy en día, todas las conceptualizaciones y convencionalismos sociales son Número publicado el 20 de diciembre de 2011 URL: http://revistadigital.eae.fcs.ucr.ac.crl 
Revista Gestión de la Educación, Vol.1, №2, pp.144-165, ISSN 2215-2288, julio-diciembre, 2011

puestos a prueba, pues los avances de la ciencia y la tecnología siguen evolucionando y con ellos, la sociedad y las personas mismas. Todo este proceso evolutivo ha generado dentro de la sociedad el advenimiento de un nuevo tipo de sujeto, dentro de un período histórico, llamado postmodernismo. Este nuevo sujeto postmoderno se caracteriza, de acuerdo con Rojas (1998), por su mediocridad, su relativismo axiológico y pluralidad de ideas. Esta nueva génesis antropológica le designa como "hombre light", así lo determina:

El hombre "ligth" no tiene referente, ha perdido su punto de mira y está cada vez más desorientado ante las grandes interrogantes de la existencia. Esto se traduce en cosas concretas que van desde no poder llevar una vida conyugal estable a asumir con dignidad cualquier tipo de compromiso serio. (p. 14)

Otra característica de este sujeto, este ser postmoderno según Rojas (1998), es relativamente vulnerable, producto de un nihilismo en el cual se pierde el sentido de la vida y del mundo, es un existencialismo en el cual el mismo hombre es convertido en el más inhóspito de los huéspedes de este mundo.

Todo esto se convierte en un reto y una oportunidad para la educación, la cual debe también ir evolucionado en la búsqueda de alternativas viables para la solución de las diferentes problemáticas que aquejan a la sociedad, enfatizando sobre todo en su naturaleza formativa y humanizadora.

Para esta sociedad, resulta muy importante la toma de conciencia por parte de cada persona, lo que enfatiza en la utilización de sus potencialidades, sus competencias y la creatividad. Esta creatividad en un nivel educativo se debe visualizar como un factor determinante en los procesos de construcción y deconstrucción de la realidad social en la que viven las personas, por el uso de la técnica, la tecnología y del ingenio creativo, para buscar alternativas y soluciones prácticas a los nuevos problemas que se le presentan.

Actualmente esas potencialidades y competencias se ponen a prueba, principalmente en lo que compete al ámbito de la educación, a la cual deben las personas hacer frente, a partir de soluciones adecuadas a las circunstancias reales en las que se desenvuelven, inmersas en una sociedad compleja que muchos conciben con pesimismo 
Revista Gestión de la Educación, Vol.1, N², pp.144-165, ISSN 2215-2288, julio-diciembre, 2011

y lo que se constituye para algunos en una transformación axiológica, fruto del fenómeno de la aculturización.

Este ingenio y creatividad humanos incide también en lo que compete a la conformación de la familia y su rol de educadora en la formación de personas felices, comprometidas con el humanismo y sobre todo, con valores. Los valores dentro de este esquema de humanización, juegan un papel importante en lo que concierne a la formación en el liderazgo que puede ayudar al ser humano a valorarse como persona y sujeto capaz de superarse continuamente, sin dejarse influir, ni manipular por nada, ni nadie.

En medio de un mundo en el cual la globalización influye considerablemente en los diferentes cambios sociales y culturales que sufre la humanidad, el papel de la educación es fundamental, pues ella, por su vocación formativa, debe hacer frente a los diferentes retos que esta sociedad fragmentada le presenta.

Es por esto que, la formación en liderazgo se debe convertir en un componente sustancial del currículo educativo costarricense, mediante su evidencia en cada uno de los ciclos que componen el sistema de educación nacional. Se debe priorizar este tipo de formación, por el carácter multidimensional y multifacético de la realidad.

El liderazgo desde esta perspectiva, se visualiza como la influencia que se ejerce en el comportamiento de las personas o grupos para el alcance de los objetivos, por lo que influye de forma muy notoria en toda organización institucional. Según Rosales (2007), un líder educativo en su institución educativa, se debe caracterizar por tener:

- Una dirección y una visión de futuro.

- Una conducta ejemplar, habla con hechos más que con palabras.

- Trabajo en equipo.

- Motivación e inspiración.

- Generador de cambios, en búsqueda de la excelencia.

Liderazgo es un mensaje de progreso y humanidad lleno de posibilidades; de confianza, visión y destino para las personas y las organizaciones. Su estudio es una puerta abierta a la esperanza, porque su fin es encontrar respuestas que satisfagan Número publicado el 20 de diciembre de 2011 URL: http://revistadigital.eae.fcs.ucr.ac.crl 
Revista Gestión de la Educación, Vol.1, N², pp.144-165, ISSN 2215-2288, julio-diciembre, 2011

aquellas necesidades de las personas y los grupos sociales, de autonomía y responsabilidad, creatividad y realización personal. Liderazgo "es la influencia que puede ser determinante para el desarrollo de las personas y organizaciones" (Linch, citado por Rosales, 2007, p.29).

El Estado costarricense debe posibilitar las condiciones necesarias para una adecuada formación y ejercicio del liderazgo en los docentes y en los alumnos. Este tipo de gestiones implica la toma de decisiones que busquen la promoción de "una cultura de participación efectiva de los profesores para el logro y mejora de su propio quehacer y de los objetivos declarados en el proyecto educativo de la institución escolar" (Uribe, 2007, p.108). Esta cultura, según el criterio de Jennings (2003) debe estar basada en:

- Un conjunto de valores muy arraigados.

- Una secuencia de trabajo eficientemente organizada y sistematizada.

- Un ambiente en el cual el trabajo se hace conforme a las "mejores prácticas".

- Un deseo compartido de eliminar el desperdicio y alcanzar un nivel elevado de productividad.

Asimismo, un ambiente competitivo en el cual cada uno de los actos realizados sirve de punto de partida para el mejoramiento continuo y para construir una cultura eficaz dentro de la institución Jennings (2003), requiere:

- Tener un gran objetivo.

- Poder de convencimiento para todos y voluntad de trabajo.

- Decir siempre la verdad en la comunicación.

- Eliminar todo aquello que signifique un obstáculo para el crecimiento.

- Valorar a las personas.

- Cuestionarse constantemente.

- Evitar el desperdicio.

- Mejoramiento continuo.

- Remuneración justa para impulsar la cultura.

Número publicado el 20 de diciembre de 2011 URL: http://revistadigital.eae.fcs.ucr.ac.crl 
Revista Gestión de la Educación, Vol.1, N², pp.144-165, ISSN 2215-2288, julio-diciembre, 2011

- Empleo acertado de la tecnología.

En el campo fenomenológico el modelo tradicional de liderazgo relacionado únicamente con el autoritarismo y el control, tiene que trascenderse. Esto porque en la actualidad es necesario practicar un estilo diferente de liderazgo, más enfocado en la participación y en la delegación de funciones, es decir, un nuevo enfoque que busque no solo la transformación del sujeto, sino también de su organización. Concentrado sobre todo en la manera y en las formas en que se realizan las diferentes actividades que las instituciones realizan.

Hay que fomentar un liderazgo más cercano y directo con el contexto, no siendo exclusivamente directivo, sino más bien participativo. Entonces, ¿cuál es el significado del concepto de liderazgo?. Desde este punto de vista, el liderazgo se constituye en una actitud hacia la vida y una aptitud para poder reforzarse como persona y para fortalecer a los demás. Se puede decir que el liderazgo es fundamental para una gestión educativa de calidad; sin embargo, hay que distinguir entre el liderazgo en sí y lo que significa la gestión. Ambos son conceptos que expresan algo distinto, pero que complementados entre sí, se constituyen en pilares fundamentales para el crecimiento integral.

El currículo educativo nacional y las instituciones educativas de Costa Rica, deben caracterizarse no solo por forjar educadores y educandos con muchos conocimientos, sino también por formar líderes constructivos de la sociedad, esto es lo que en realidad busca establecer el liderazgo transformacional.

Un "nuevo liderazgo": el transformacional que aparece en la reconceptualización de los años ochenta, un liderazgo carismático, visionario, transformativo, más flexible e inclusivo, comunitario y democrático. El que en lugar de acentuar la dimensión de influencia en los seguidores o en la gestión, se enfoca en la línea de ejercer el liderazgo mediante significados (visión, cultura, compromiso, etc.) de un modo compartido con los miembros, imbuyéndolos en un sentido más alto a los propósitos inmediatos. (Salazar, 2006, p.2)

Número publicado el 20 de diciembre de 2011 URL: http://revistadigital.eae.fcs.ucr.ac.crl 
Revista Gestión de la Educación, Vol.1, №2, pp.144-165, ISSN 2215-2288, julio-diciembre, 2011

Son por lo tanto, métodos de actuar diferentes, y cada uno con sus propias funciones y actividades. Pero ambos se focalizan hacia la búsqueda de un mejoramiento continuo de las instituciones, en medio de un mundo de contrastes y de cambios constantes.

El informe de la Organización para la Cooperación y Desarrollo Económico [OCDE], "Escuelas del futuro" en el año 2001, citado por Mulford (2006), hace todo un análisis con respecto del estado de la educación en la actualidad, la calidad educativa y su proyección hacia el futuro. Por esto, la importancia que cobra formar agentes multiplicadores del liderazgo, y que esos agentes sean partícipes de las decisiones que contribuyan a un mejoramiento continuo de su gestión administrativa. Asimismo, Salazar (2006) analiza el impacto que produce el ejercicio de un adecuado liderazgo en la eficiencia escolar es de suma importancia para poder gestionar instituciones más eficientes.

\section{El concepto de calidad en educación}

El significado atribuido a la calidad educativa, en la actualidad, se puede conceptualizar desde diversas perspectivas. Para Rosales (2007), una de ellas se presenta cuando se relaciona este concepto con un enfoque en el cual lo más importante es la eficacia, entre lo que se enseña y lo que los alumnos aprenden o se presume que deben aprender, aquello que está establecido en los planes y programas curriculares, en un determinado ciclo o nivel. Su énfasis está puesto en la asistencia, de tal forma que con el paso por el sistema los estudiantes aprendan. En este enfoque los resultados logrados por la acción educativa se constituyen en su prioridad.

Otra conceptualización del término calidad educativa, según Rosales (2007), es aquel en la cual lo que se aprende en el sistema cobra relevancia en términos individuales y sociales. Una educación de calidad, de acuerdo con este enfoque es aquella cuyos contenidos responden a lo que el individuo necesita para su desarrollo integral (moral, física, intelectual, afectiva y como persona, entre otros), y que procura de este individuo Número publicado el 20 de diciembre de 2011 URL: http://revistadigital.eae.fcs.ucr.ac.crl 
Revista Gestión de la Educación, Vol.1, №2, pp.144-165, ISSN 2215-2288, julio-diciembre, 2011

una adecuada inclusión al contexto social en el cual se desarrolla en diferentes ámbitos: político, económico, social. Para este enfoque son prioritarios los fines atribuidos a la acción educativa, concretados en los diseños y contenidos curriculares.

Una tercera conceptualización en relación con la calidad educativa, según esta autora, es la que hace referencia a la calidad de los procesos y los medios que el sistema educativo ofrece a los estudiantes en un adecuado contexto físico para el aprendizaje.

Para esto debe contarse con un grupo de docentes bien preparados en el arte de enseñar, contar con los recursos aptos para la enseñanza aprendizaje y establecer métodos adecuados para la enseñanza, poniendo énfasis sobre todo en el análisis de los medios empleados en la actividad educativa.

Central a esta concepción es, entre otras, la consideración de que el líder ha de articular una visión para la organización, comunicarla a los demás y lograr de ellos asentimiento y compromiso. El líder transformacional se esfuerza en reconocer y potenciar a los miembros de la organización y se orienta a transformar las creencias, actitudes y sentimientos de los seguidores, pues no solamente gestiona las estructuras sino que influye en la cultura de la organización en orden a cambiarla.

\section{Liderazgo para mejoramiento de la calidad educativa}

Para poder hacer efectivo un liderazgo de calidad en el sistema educativo costarricense es urgente que se empiece por hacer un replanteamiento de su estructura, para esto hay que preguntarse ¿Qué tipo de educación sirve mejor a la sociedad ahora y en el futuro? ¿Cuál es el enfoque de liderazgo que se necesita? Para responder a estas preguntas, lo primero que se debe hacer es que a nivel educativo han de promoverse procesos, acciones, directrices, metodologías que promuevan un liderazgo efectivo y transformacional todo esto como parte de un proyecto educativo institucional.

Otro factor de suma trascendencia para edificar una institución educativa de calidad, tiene que ver con el tipo de liderazgo que ejerza el director, pues este lejos de ser un personaje lejano y con poder, más bien, tiene que ser un líder instructivo fuerte, proactivo y abierto al cambio, estimulador del personal, entre otros.

Según Mulford (2006), la calidad educativa incluye asuntos como la enseñanza y 


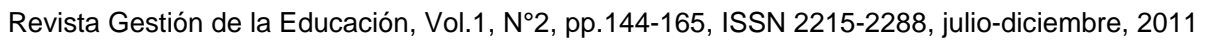

aprendizaje individual, áreas de equidad como la inclusión, las áreas de eficacia como la autonomía, la descentralización, la responsabilidad y el liderazgo. Los contenidos relacionados con la educación permanente, incluyen educación y formación vocacional y la educación de los adultos. Todo esto enmarcado dentro de un proceso de transformación constante, y sobre todo de innovación. Esto implica pasar de los viejos esquemas tradicionales o enfoques clásicos del liderazgo, hacia enfoques más innovadores, democráticos y participativos.

Lo que se pretende es hacer copartícipes a los docentes y padres de familia en los procesos y las prácticas institucionales, las cuales se deben desarrollar a través de diferentes líneas de acción. Entre estas líneas se encuentran:

- Participación de profesores y padres en procesos y actividades de la institución. Trabajo en equipo e implicación en el proceso.

- Proyecto educativo. Planeamiento con normas, valores. Programas de formación en función de las necesidades de la institución. Y fomentar una cultura de evaluación constante entre todos los agentes que intervienen en el proceso.

- Promover el desarrollo de las habilidades y competencias profesionales para cada docente. Conocimiento personal, utilización racional del tiempo.

- Planificación y coordinación curricular entre los profesores.

- Capacitación constante y actualizada, en el ejercicio pedagógico y didáctico. Formación permanente.

- Estimular constantemente la motivación y el autoconocimiento (Sentido de vida).

- Hacer de cada institución, una escuela de emprendedores y de liderazgo (Facilitadores).

- Incentivar una comunicación efectiva entre las partes (Asertividad).

- Hacer partícipe de los procesos a la comunidad educativa en general, creando redes de apoyo. Autonomía, colaboración y participación.

Entender la institución educativa de acuerdo con estos lineamientos es visualizar toda su estructura y composición como una organización que aprende, pues ella misma Número publicado el 20 de diciembre de 2011 URL: http://revistadigital.eae.fcs.ucr.ac.crl 
Revista Gestión de la Educación, Vol.1, N², pp.144-165, ISSN 2215-2288, julio-diciembre, 2011

es cogeneradora y facilitadora de liderazgo efectivo en cada uno de sus integrantes, tomando en cuenta que esto es un proceso constante de formación, de transformación y de perfección continua.

Crear una cultura organizativa de aprendizaje continuo y de trabajo cooperativo es de suma relevancia, puesto que en cierta forma en todo trabajo tanto los triunfos como los fracasos, tiene que ser de conocimiento público, hacer partícipes a los demás los compromete con su quehacer diario. Por esto todo educador que sirva como modelo de liderazgo debe tener como principal consigna el éxito en todas y cada una de las tareas que realiza, sobre todo en su campo de estudio y por los estudiantes. Todo proyecto educativo de una institución, tiene que estar fundamentado en un, "objetivo [...] genuino y auténtico" (Jennings, 2003. p.29).

Según este autor, lo que se busca es no solo tener un objetivo claro, sino también se trata de vivir de acuerdo y por ese objetivo, de ir guiando el proceso de edificación en el cual todos deben colaborar en la construcción de una cultura institucional acorde con los principios establecidos "se trata de construir una cultura. ¿Cómo diablos podría hacerse sin comunicar constantemente lo que somos, lo que defendemos y hacia dónde vamos?" (Jennings, 2003, p.35).

Por esto, es preciso que tanto los directores como los docentes mismos tomen conciencia de la importancia que tiene dentro del contexto educativo nacional la formación de líderes, y fomentar el liderazgo transformacional. Esto a su vez significa que se genere dentro de la misma una cultura de transformación en la cual las habilidades, los valores, las competencias profesionales, busquen siempre una mejora y dé aprendizaje permanente.

"En las organizaciones que aprenden se resaltan dos aspectos clave: el valor del aprendizaje como base de la organización y el desarrollo de las personas para implementar nuevas prácticas en la institución donde trabajan" (Uribe, 2007, p.111).

Por esto es imprescindible, proporcionar a los profesores los recursos necesarios, para que no solo puedan convertirse en trasmisores de cultura, sino también en transformadores de la realidad, de tal forma que se tengan las destrezas y competencias necesarias para poder realizar los controles necesarios y sean al mismo tiempo 
Revista Gestión de la Educación, Vol.1, N², pp.144-165, ISSN 2215-2288, julio-diciembre, 2011

formadores de un pensamiento crítico, que sepan educar en la toma de decisiones, aspectos muy importantes en la actualidad.

Esta nueva reconceptualización del liderazgo tiene que responder a las demandas que el contexto sociocultural de este siglo XXI exige, en medio de una sociedad catalogada por muchos como postcapitalista, postmoderna, postburocrática.

El liderazgo del siglo XXI se tiene que caracterizar por su flexibilidad, su adaptabilidad, su descentralización y autonomía de todas las instituciones y organizaciones. Más que un ejercicio del poder, se tiene que orientar hacia enfoques más holísticos y sistémicos, de tal forma que cada parte que compone una institución educativa, sea un componente importante de un sistema en el cual cada una de sus

partes estén interconectadas y se afecten mutuamente. Según Mulford (2006), los efectos de un liderazgo efectivo en los centros resaltan:

- El liderazgo es un factor importante, que contribuye a lo que aprenden los estudiantes.

- Los líderes indirectamente contribuyen al aprendizaje de los alumnos, sobre todo por su influencia sobre otras personas. Para esto dedican tiempo y atención.

- Cuatro son las bases de liderazgo con éxito: formación de las personas, marcar las directrices, gestionar programa de instrucción.

- Rediseño de la organización.

Para el logro de esto, el líder debe crear una cultura institucional de trabajo en equipos, de servicio y de identificación con los objetivos que se propongan, obliga a que cada uno de los integrantes que laboran dentro de la institución se sientan partícipes y corresponsables de sus acciones, tomando conciencia de que cada acción buena o mala que realicen, afecta directamente a la organización y a los objetivos propuestos, puesto 
Revista Gestión de la Educación, Vol.1, №2, pp.144-165, ISSN 2215-2288, julio-diciembre, 2011

que la organización debe funcionar como un todo sistémico. En el fondo lo que se busca es potenciar un liderazgo transformador tanto dentro como fuera de la institución.

Para el éxito de esta nueva cultura institucional, y esta nueva opción de liderazgo, caracterizado por su flexibilidad, su adaptación a las circunstancias y al contexto en el que se desenvuelve, estando abiertas al cambio es importante que cada uno de sus integrantes, aprenda a construir visiones compartidas, aprender a dominarse a sí mismos, buscar mejorar sus modelos mentales, a trabajar en equipo y adquirir un pensamiento sistémico.

Este nuevo enfoque del liderazgo se establece como un factor clave en los procesos de mejoramiento de las instituciones educativas, la efectividad y mejora de los resultados, puesto que un buen líder cambia su entorno y un buen liderazgo transforma tanto la instituciones como a las personas que en ellas laboran, por lo tanto se constituye en un factor determinante en la creación de culturas de calidad, puesto que ya la responsabilidad y el compromiso no estará a cargo de una sola persona, sino que es un liderazgo compartido y la responsabilidad es mutua. De esta forma tanto los profesores, como los alumnos y padres de familia, se convierten en codiseñadores, productores y asesores.

A esto Mulford (2006) agrega, que para que pueda ser realidad una educación con calidad, la formación de capital social es esencial para un liderazgo eficaz. Por otra parte, un buen liderazgo debe promover a nivel organizacional la creatividad; la adaptación al cambio; cuando existe una real preocupación por la situación de los subordinados y se promueve la criticidad y la proactividad, lo que se pretende es crear "comunidades de liderazgo" (Uribe, 2007, p.111).

Al mismo tiempo el liderazgo implica también estar consciente de los valores, creencias que se poseen, aprender de los errores, asumir compromisos, capacidad de escucha y sensibilidad ante los problemas propios y ajenos. A este tipo de liderazgo se le denomina como transformacional; Bryman (1996) menciona que "el liderazgo transformacional se sitúa dentro de los nuevos enfoques sobre el liderazgo, con una connotación orientada a la participación y flexibilidad en la organización. Abandonando las teorías del superhombre y su fuente de influencia se centra más en dar significado a la 
Revista Gestión de la Educación, Vol.1, N², pp.144-165, ISSN 2215-2288, julio-diciembre, 2011

tarea. De este modo, la visión, la cultura y el compromiso pasan a ser sus dimensiones teóricas más esenciales" (citado por Salazar, 2006, p.6).

De esta forma, con el liderazgo transformacional -el cual se define como la forma de proceder de los directores, cuya tendencia es la de convertir a los maestros y docentes en líderes de la actividad educativa, por medio de la motivación y la toma de conciencia de su papel- se pretende hacer partícipes a los docentes de los resultados que se obtienen en las gestiones administrativas de la institución, generando con esto grandes expectativas. Esto por lo tanto representa una cultura de cambio.

\section{Rasgos que caracterizan a un educador líder}

Un líder en educación tiene que tener ante todo vocación de educador, este es un factor determinante para poder realizar una gestión educativa de calidad. Es importante por esto que se perfile un tipo de educador líder en su área y en su forma de ser y de actuar, en otras palabras debe modelar conductas de liderazgo. El liderazgo se puede aprender, no necesariamente un buen líder, es un gran educador.

Entre las variables que según Bass, citado por Bernal (2007), determinan y caracterizan a un líder educativo se encuentran:

- Posee carisma, esto le identifica como un líder carismático que trasmite confianza y respeto entre sus adeptos. Con esto busca generar lealtad y compromiso con los objetivos de la organización. De tal forma que sus propias conductas caracterizadas por su compromiso y honestidad, permite a sus subalternos constatar su coherencia, esto al mismo tiempo provoca un respeto hacia su vida y complacencia en sus colaboradores.

- Consideración individual, este aspecto hace referencia a la atención individualizada que le presenta a cada una de las personas que están a su cargo. Se preocupa por sus situaciones personales tratando individualmente todas aquellas realidades de las personas, siendo sensible a sus necesidades e 
Revista Gestión de la Educación, Vol.1, №2, pp.144-165, ISSN 2215-2288, julio-diciembre, 2011

intereses. Todo esto logra gracias al alto grado de empatía y de accesibilidad que posee.

- Estimula intelectualmente, esto tiene que ver con el alto grado de innovación que posee, pues busca favorecer nuevos enfoques y sobre todo la creatividad. Enfatiza en la inteligencia y la racionalidad, sobre todo en la resolución de conflictos. Todas estas iniciativas buscan un pleno desarrollo de las capacidades y competencias personales de los miembros de su organización. Es por lo tanto, un mentor, un facilitador de conocimientos, un motivador de su personal y sobre todo un animador líder.

- Es un inspirador, seduce a los demás con su forma de ser y de actuar, su visión de futuro inspira en ellos optimismo, entusiasmo y esperanza, en la consecución de los objetivos y los proyectos programados, desarrollando, por lo tanto, un fuerte sentido de identidad, por la institución en la cual labora.

- Fomenta la tolerancia psicológica, esta cualidad se hace efectiva por medio del gran sentido común que posee, sobre todo para indicar las equivocaciones y para resolver los conflictos y las situaciones difíciles que se le presentan, tolera los errores ajenos y los suyos propios para el mejoramiento de todos. Todas estas situaciones, las resuelve con sentido del humor.

- Es un participante activo, con esto busca desarrollar la capacidad para construir un liderazgo compartido, esto lo logra promoviendo una cultura de participación, en la cual se pueda dar un consenso entre los valores que deben identificar la institución. Cree firmemente en el trabajo en equipo, pues lo considera como una estrategia que produce la sinergia para la obtención de resultados óptimos. Para esto busca mantener una comunicación tanto horizontal como verticalmente.

- Su actuación como directivo, pues se caracteriza por su gran adaptación a los cambios, no teme tomar riesgos, y es eficaz en la toma y ejecución de las decisiones. Tiene un gran dominio del estrés propio.

Un líder puede poseer unas cualidades innatas, o también puede adquirirlas, aquí 
Revista Gestión de la Educación, Vol.1, №2, pp.144-165, ISSN 2215-2288, julio-diciembre, 2011

lo importante es que conozca sus propias cualidades. Todo educador debe encarnar los valores fundamentales y humanistas que toda actividad educativa posee en sí misma. Acciones como el autoconocimiento personal, lo inducen a un proceso de automejoramiento y a un reconocimiento de sus debilidades, primero él debe estar convencido de lo que piensa y siente, y ponerlo en práctica. Esto significa que posee una base suficientemente magnánima como para poderse sostener con autoridad y respeto.

Según Blanchard (2005),

- Se conoce y se da a conocer a los demás.

- Encarna los valores de su organización.

- Posee humildad y pide ayuda.

- Es auténtico, sin pretensiones ni arrogancia.

- $\quad$ Invierte tiempo en sí mismo.

- Disfruta lo que hace. Se apasiona por lo que hace.

- Es servicial, posee voluntad de servicio.

- Es detallista y cautivador.

- Sabe escuchar y es observador

- Es autodidacta (se cultiva a sí mismo)

- Es selectivo (sabe seleccionar a su personal)

- Tiene visión. Se orienta hacia el futuro.

- Enseña para el triunfo. Se alegra de los triunfos ajenos.

- Potencia las fortalezas de sus empleados.

- Valora los resultados y las relaciones.

Hay que enfatizar sobre todo en este ser visionario que un líder debe tener. Esto significa que a pesar de los problemas que tiene que enfrentar, y el contexto en el cual se desenvuelve, analiza las situaciones con optimismo y esperanza. Siendo creativo, reinventando constantemente soluciones alternativas que puedan satisfacer las necesidades que tienen las personas.

Según Hunter (1996), además de las cualidades expuestas, un líder debe tener: Número publicado el 20 de diciembre de 2011 URL: http://revistadigital.eae.fcs.ucr.ac.crl 
Revista Gestión de la Educación, Vol.1, №2, pp.144-165, ISSN 2215-2288, julio-diciembre, 2011

- Paciencia: muestra dominio de sí mismo.

- Indulgencia: no guarda rencor cuando le perjudican.

- Afabilidad: sabe prestar atención, aprecia y anima a los otros.

- Sacrificio: busca lo mejor para los otros.

- Respeto: trata a los otros como si fueran gente importante.

- Honradez: está libre de engaños.

Considerando que la educación es un servicio que se brinda a los demás, es por lo tanto la donación que hace un educador de sí mismo, para los demás, un ejercicio constante de servir, esta debe ser la principal característica de un educador líder.

La autodidaxia, en un educador líder, se convierte en un factor determinante, en lo que compete a la formación permanente y en la actualización constante en lo que respecta del conocimiento y al mundo en el cual se tiene que desenvolver. La sociedad en la actualidad exige para cada cuestionante que surja del sujeto, una respuesta acertada y actualizada, no basada en mitos y tabúes, ni tampoco en dogmas. Sino un conocimiento actualizado y un constante ejercicio de la flexibilización.

La educación vista como un carisma que requiere de un educador líder con carisma también, él mismo debe poseer, como se vio anteriormente, una serie de destrezas, tales como la autodisciplina, la valentía, el conocimiento de sí mismo, la humildad, entre otros. Un educador líder debe ser un agente, un medio por el cual se constituyan otros líderes, "los líderes tienen empatía por otros y una aguda habilidad de encontrar lo mejor en las personas... no lo peor...al preocuparse verdaderamente por ellos" (Maxwell, 1999, p.93).

\section{Horizonte próximo de la educación costarricense}

La educación formal costarricense actual enfrenta una serie de retos. Entre estos se encuentra el fenómeno de la globalización y los cambios vertiginosos que el paradigma científico tecnológico, han hecho en la forma de ser y de actuar de las personas, todo esto Número publicado el 20 de diciembre de 2011 URL: http://revistadigital.eae.fcs.ucr.ac.crl 
Revista Gestión de la Educación, Vol.1, №2, pp.144-165, ISSN 2215-2288, julio-diciembre, 2011

afecta al quehacer educativo mismo.

Ninguna de las etapas de la historia de la humanidad ha escapado de los retos que la evolución misma del pensamiento ha traído. Dentro de esta evolución epistemológica, el ser humano ha buscado dar respuestas a cada uno de los diferentes dilemas que se le han presentado, por medio de su ingenio y creatividad, ha elaborado diferentes formas para construir alternativas que faciliten y hagan más feliz su vida.

Ese ingenio y creatividad, en el contexto educativo, es puesto a prueba en la actualidad, sobre todo en aspectos relacionados con el relativismo axiológico y el pluralismo ideológico en el que se desenvuelve. A esta nueva etapa de la historia humana algunos la denominan como postmoderna, la cual se caracteriza por el desarrollo científico y tecnológico expresado en las diferentes tecnologías de la información que están al alcance del ser humano y su influencia en la forma de pensar y de actuar de este. Para Mardones (1988), también se percibe la postmodernidad como:

La entrada en un tiempo en el que los acontecimientos se atropellan (...) una multiplicación y saturación de intercambios hacen más densa la masa social, los "media", la informática, los circuitos y las redes influyen en la rotura de la órbita referencial de las cosas. (p.65)

Es una obligación por tanto de todo líder educativo analizar desde una perspectiva crítica el contexto en el cual se desenvuelve o está inserta la institución, examinando las diferentes problemáticas que se suscitan y que consumen a las familias y los jóvenes. Conflictos relacionados con la pobreza, la drogadicción, la prostitución infantil, el abuso, la violencia doméstica, la deserción escolar, el desempleo, la indiferencia familiar, es decir, todas aquellos problemas que de una u otra forma afectan directa o indirectamente el proceso de enseñanza aprendizaje de los niños (as) y jóvenes e interrumpen su formación integral.

Ante estas situaciones que apremian tanto al sistema familiar, como al educativo, cobra importancia el rol que juegan las instituciones educativas, el liderazgo y convicción de sus directores y docentes, en la formación de la conciencia de sus educandos. El aula 
Revista Gestión de la Educación, Vol.1, N², pp.144-165, ISSN 2215-2288, julio-diciembre, 2011

debe dejar de ser un recinto organizado militarmente y de reproducción social y convertirse en una oportunidad que tienen tanto los docentes como los estudiantes para ejercitarse en el liderazgo y crecer integralmente.

Para el logro de esta faena es importante que todas las autoridades institucionales de este siglo XXI cambien su forma de concebir la educación y la administración misma, pues los tradicionales métodos de administración, con líneas de jerarquía y de control burocrático ya no son efectivos. Los líderes de este siglo XXI, se deben destacar por su ejemplo de vida, su flexibilidad y adaptabilidad a las condiciones, la eficacia en sus decisiones, y sobre todo por ser un agente de cambio positivo.

Un educador líder tiene una misión humanista, debe estar informado acerca de los descubrimientos científicos, la tecnología, conocer acerca de la importancia de aspectos tales como la motivación humana y la formación de equipos, el trabajo en equipo, la formación de líderes, entre otros. Un educador de este siglo XXI debe ser un líder en la adquisición y generación del conocimiento, debe conocer de todo un poco y estar actualizado.

Todo esto obliga al sistema educativo nacional a buscar un rediseño curricular, procurando responder a las necesidades actuales que demandan los estudiantes y la sociedad en general.

Nos encontramos con una nueva generación de alumnos, lo que Bill Gates denomina la generación "i” (información e Internet). Para Castells (1999), citado por Uribe (2007) en la formación de esta generación podremos lograr que esté "desinformada" (solo entiende imágenes), "sobreinformada" (exceso de información sin selección ni comprensión) o informada (selecciona, ordena y comprende la información).

De allí, la insistencia de un replanteamiento educativo, que no solo forme personas con muchos conocimientos, sino también con un alto nivel educativo que colabore para que se adapten bien a las condiciones que su entorno le presenta, potenciando sus habilidades y sus ideas, su nivel de criticidad y de análisis social.

En esta sociedad del conocimiento y de la información, valores como la responsabilidad, la creatividad y la innovación se constituyen en pilares fundamentales para su desarrollo integral. Para esto los docentes tienen que cumplir con la misión de 
Revista Gestión de la Educación, Vol.1, N², pp.144-165, ISSN 2215-2288, julio-diciembre, 2011

enseñar a asimilar y de seleccionar aquellos contenidos relevantes, al mismo tiempo que interrelacionarlos y ponerlos en práctica. Esto significa por lo tanto, que deben trascender los viejos esquemas de enseñanza dejando de ser "meros transmisores de conocimiento o de información" (Uribe, 2007, p.6).

Todas estas situaciones implican que tanto las autoridades del gobierno, como la población civil se cuestionen: ¿Cuál es el tipo de liderazgo que necesitan las instituciones educativas actualmente? ¿Cuál es el tipo de educación que necesitan nuestros estudiantes? ¿Qué es lo que a ellos les interesa? "Quizás el cambio más importante por su dificultad es tener la capacidad de aprender cosas y materias más allá de lo convencional [...] el próximo desafío será para los sistemas de enseñanza tradicionales, que se verán afectados por las modernas tecnologías" (Drucker, 2000, p.12).

En lo que compete a la política educativa nacional y su vinculación con la formación en el liderazgo, sus lineamientos no lo expresan de forma directa; sin embargo, se puede inferir de estos aspectos relativos a la formación integral de las personas que tienen que ver con el liderazgo.

En el artículo 2 de la Ley Fundamental de Educación (1957), se expresa que entre los fines de la educación costarricense está la formación de ciudadanos amantes de su Patria, conscientes de sus deberes, de sus derechos y de sus libertades. Además, la educación debe contribuir al desenvolvimiento pleno de su persona.

Esto solo se puede lograr según esta ley si a los educadores mismos se les asegura que posean los conocimientos necesarios para una buena labor docente, el aprecio por los valores universales y la comprensión de que su misión de educador trasciende cualquier límite y al mismo tiempo cuando se suministre por parte de los centros educativos la información necesaria, pero además cuando se pueda integrar a los padres de familia y a los alumnos para que participen, comprendan y apoyen el proceso. "Nuestros alumnos buscan a veces desesperadamente, un propósito y un sentido a sus vidas, y cuando no se satisface esa necesidad, se vuelcan a las drogas, la violencia y toda una legión de calamidades con las que intentan colmar ese vacío" (Hunter, 1996, p.165).

En Costa Rica, se debe realizar una lectura de la realidad propia de su contexto y 
Revista Gestión de la Educación, Vol.1, №2, pp.144-165, ISSN 2215-2288, julio-diciembre, 2011

de los cambios que el contexto internacional demanda. Esto de acuerdo con la política educativa implica un cambio en sus concepciones de desarrollo, analizado desde la perspectiva humanista, ecológica, tecnológica y espiritual.

Estos desafíos para el sistema educativo nacional, tienen que ver sobre todo con las concepciones deshumanizantes y deshumanizadoras, lo cual obliga a la educación misma a entrar en un contacto directo con su entorno. Este contacto directo se debe caracterizar por tener una visión crítica del mismo, y esto al mismo tiempo implica una transformación radical de su estructura administrativa y operativa.

"La concreción de un proyecto de calidad de la educación, solo puede llevarse a la práctica, si la "institucionalidad" renueva sus estructuras concentradas, centralizadas, aisladas y burocráticas por procesos integrados, orientados hacia una gestión de calidad, al servicio de los educadores y del público en general" (Gutiérrez, 2005, p.4).

La política educativa de Costa Rica posee una visión integral del ser humano, sus bases se sustentan en tres visiones filosóficas como la humanista, la racionalista y la constructivista. Estas visiones pretenden la formación de personas plenas, realizadas, realistas y constructivas, en el fondo lo que buscan es la formación integral de su ser y al mismo tiempo impulsar a ser un analista crítico de su entorno. Desde este punto de vista se concibe al ser humano como un ser capaz de trascenderse a sí mismo, un ser humano con potencialidades y que siempre está en constante búsqueda de la perfección y así crecer en armonía con su entorno.

Esta armonía con su entorno implica que este ser humano sea un propulsor del bien común y por lo tanto, de un mejoramiento de calidad de vida. Para cumplir con este cometido la educación costarricense se debe perfilar hacia un modelo más participativo, cogestionario y autogestionario. En otras palabras pasar de la palabra a la acción, de la teoría a la praxis y no quedarse con meras elucubraciones filosóficas.

Estos lineamientos presentes en ella obligan a que la educación misma produzca personas líderes curriculares, en especial potenciar el rol de los directores como mediadores e implicar a los docentes mismos sobre todo en la toma de decisiones curriculares e innovaciones. Para lograr estos cometidos es importante tomar en cuenta que esta transformación de la concepción y operacionalización del currículo nacional, 
Revista Gestión de la Educación, Vol.1, N², pp.144-165, ISSN 2215-2288, julio-diciembre, 2011

debe tener como metas:

- El desarrollo integral de la persona y las personas.

- La contextualización y regionalización curricular.

- El mejoramiento de la calidad de vida de las personas.

- La formación de líderes íntegros.

- Rescate y fomento de los valores y la humanización de la sociedad.

Propiciar un liderazgo transformacional y fomentar escuelas y colegios que aprenden, se constituye en dos de los retos más importantes que tiene el sistema educativo costarricense. Hasta que no seamos capaces de iniciar una reestructuración en cada una de las áreas que competen a la educación, será muy difícil que estos objetivos se concreten. Hay que simplificar los procedimientos, eliminado todos aquellos procesos burocráticos que se convierten en un obstáculo para el desarrollo y el crecimiento tanto de líderes como de sus instituciones mismas.

Por esto, involucrar a toda la comunidad educativa en un proceso de crecimiento, de automejoramiento, y de toma de decisiones se convierte en un indicador de progreso, de liderazgo efectivo y de calidad educativa. Si se logran estas metas, a nivel nacional toda la sociedad gana y con esto se garantiza el desarrollo económico y social del país. Esto es posible haciendo que las organizaciones educativas sean auténticas escuelas de formación de líderes. Escuelas encaminadas hacia la formación del liderazgo docente y del liderazgo de los estudiantes; solo así se podría pensar en que nuestro sistema educativo busque la formación de personas integrales y sobre todo felices.

\section{Referencias bibliográficas}

Bernal, J. L. (junio, 2007). Un liderazgo para el siglo XXI. Revista Digital Educación Social, 3 (19). Recuperado de www.revistaglobal.org/default.php.

Blanchard, K. (2005). El secreto. Lo que los grandes líderes saben y hacen. Bogotá, Número publicado el 20 de diciembre de 2011 URL: http://revistadigital.eae.fcs.ucr.ac.crl 
Revista Gestión de la Educación, Vol.1, №2, pp.144-165, ISSN 2215-2288, julio-diciembre, 2011 Colombia: Grupo Editorial Norma.

C.R. Asamblea Legislativa. (1957). Ley Fundamental de Educación, № 2160. Recuperado de http://www.oei.es/quipu/costarica/Ley 2160.pdf

Drucker, P. (2000). El líder del cambio. Guía del Seminario y Libro de trabajo. Madrid: Gestión y planificación integral.

Gutiérrez, C. (2005). Política educativa siglo XXI. Recuperado de www.conare.or.cr Jennings, J. (2003). Menos es más. Madrid: Editorial Norma.

Hunter, J. (1996). La paradoja. Barcelona: Urano.

Mardones, J. M. (1988). Postmodernidad y cristianismo. El desafío del fragmento. Bilbao: Sal Térrea.

Maxwell, J. (1999). Las 21 cualidades indispensables de un líder. EE.UU: Editores CaribeBetania.

Mulford, B. (2006). Liderazgo para mejorar la calidad de la educación secundaria. Revista de currículum y formación del profesorado. Recuperado de http://www.ugr.es/ recfpro/rev101ART2.pdf

Rojas, E. (1998). El hombre light. Una vida sin valores. México: BOOKET.

Rosales, M. (2007). ¿Calidad sin liderazgo? Contexto Educativo. Revista digital de Educación y nuevas tecnologías. Recuperado de http://contextoeducativo.com.ar/2000/5/nota-3.htm

Salazar, M. (julio, 2006). El liderazgo transformacional ¿Modelo para organizaciones educativas que aprenden? UNIrevista, 1(3), 1-12. Recuperado de www.alaic.net/ponencias/UNIrev Salazar.pdf

Uribe, M. (junio, 2007). El liderazgo docente en la construcción de la cultura escolar de calidad. Un desafío de orden superior. Revista PREALC, 1(1). UNESCOOREALC. Recuperado de http://www.galeon.com/documentosmc/liderazgo.pdf 